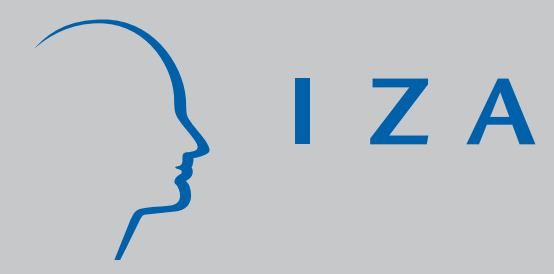

IZA DP No. 3360

Start-Up Subsidies in East Germany:

Finally, a Policy that Works?

Marco Caliendo

February 2008 


\title{
Start-Up Subsidies in East Germany: Finally, a Policy that Works?
}

\author{
Marco Caliendo
}

$I Z A$ and $I A B$

Discussion Paper No. 3360

February 2008

\author{
IZA \\ P.O. Box 7240 \\ 53072 Bonn \\ Germany \\ Phone: +49-228-3894-0 \\ Fax: +49-228-3894-180 \\ E-mail: iza@iza.org
}

\begin{abstract}
Any opinions expressed here are those of the author(s) and not those of IZA. Research published in this series may include views on policy, but the institute itself takes no institutional policy positions.

The Institute for the Study of Labor (IZA) in Bonn is a local and virtual international research center and a place of communication between science, politics and business. IZA is an independent nonprofit organization supported by Deutsche Post World Net. The center is associated with the University of Bonn and offers a stimulating research environment through its international network, workshops and conferences, data service, project support, research visits and doctoral program. IZA engages in (i) original and internationally competitive research in all fields of labor economics, (ii) development of policy concepts, and (iii) dissemination of research results and concepts to the interested public.
\end{abstract}

IZA Discussion Papers often represent preliminary work and are circulated to encourage discussion. Citation of such a paper should account for its provisional character. A revised version may be available directly from the author. 
IZA Discussion Paper No. 3360

February 2008

\section{ABSTRACT \\ Start-Up Subsidies in East Germany: Finally, a Policy that Works?*}

The German government has spent between $7 \mathrm{bn}$ and $11 \mathrm{bn}$ Euro per year on active labor market policies (ALMP) in East Germany in the last decade. The effectiveness of the most important programs (in terms of participants and spending) such as job-creation schemes and vocational training has been evaluated quite thoroughly in recent years. The results are disappointing, indicating that nearly all of these 'traditional' programs have to be rated as a failure. In light of these findings, policies to encourage unemployed people to become selfemployed gained increasing importance. We present first evidence on the effectiveness of two start-up programs in East Germany. Our findings - even though partly preliminary - are rather promising, showing that these programs increase employment chances and earnings of participants. Hence, start-up subsidies might work even in a labor market with structural problems such as the one in East Germany.

JEL Classification: J68, C14, H43, M13

Keywords: $\quad$ start-up subsidies, evaluation, effectiveness, East Germany, self-employment

Corresponding author:

Marco Caliendo

IZA

P.O. Box 7240

D-53072 Bonn

Germany

E-mail: caliendo@iza.org

* The author thanks Ulf Rinne for valuable comments. The usual disclaimer applies. 


\section{Introduction}

Faced with unemployment rates around $20 \%$ over the last decade, the German government spent between 7bn and 11bn Euro per year on active labor market policies (ALMP) in East Germany to combat this situation. The most important measures (in terms of participants and spending) during this period have been job-creation schemes and vocational training programs. The effectiveness of these programs has been evaluated quite thoroughly in recent years. Based on very informative administrative data and matching techniques, Biewen, Fitzenberger, Osikominu, and Waller (2007) evaluate the effectiveness of different training programs, whereas Caliendo, Hujer, and Thomsen (2007) concentrate on jobcreation schemes. The findings are disappointing: Biewen et al. (2007) do not find any positive effects for short-, medium- or long-term training in East Germany for women and only little evidence of positive effects for some male subgroups. Caliendo et al. (2007) show that participating in a job-creation scheme generally lowers the employment chances of participants; only long-term unemployed women seem to slightly benefit three years after programs have started. Lechner and Wunsch (2006) compare the relative effects of different programs (including different types of training, job-creation schemes and shorter measures) and conclude that all programs do not improve the employment chances or earnings of participants. Even though they note that the programs might have had other beneficial effects, judging by the main goal - integration into regular employment-nearly all of these 'traditional' programs have to be rated as a failure.

In light of these disappointing findings the Federal Employment Agency (FEA) tested a new strategy to combat the unemployment problem by turning unemployment into self-employment. Whereas in 1994 only 37,000 business start-ups by formerly unemployed individuals where funded, the number was above 350,000 in 2004 (approximately 100,000 in East Germany). This increase was driven, among other things, by a new program known as the 'start-up subsidy' (SUS, Existenzgründungszuschuss), which was introduced in 2003 as part of the Hartz reforms and implemented in addition to the already existing 'bridging allowance' (BA, Überbrückungsgeld). Both programs differ in their design, the most important difference being in respect of the amount and duration of the subsidy. While the BA pays recipients the same amount that they would have received as unemployment benefits for a period of six months (plus a lump sum of roughly $70 \%$ to cover social security contributions), the SUS runs for three years, paying a lump sum of $€ 600 /$ month for the first year, $€ 360 /$ month for the second, and $€ 240 /$ month for the third. Later on we will show that this different design also attracted different target groups. 
Since these programs are usually also associated with the hope for further positive effects, e.g., through direct job-creation, they could potentially not only decrease East Germany's persistently high unemployment rate, but increase its low (self-)employment rate as well. Looking at the FEA's spending on ALMP, we clearly see the increasing priority assigned to these programs within the overall ALMP strategy. Whereas only $1.1 \%$ of ALMP resources were allocated to these measures in 1995, this number was $8.9 \%$ in 2004 . Empirical evidence on these programs is scarce in general and non-existent for East Germany. Baumgartner and Caliendo (2007) evaluate the effectiveness of both programs in West Germany and find considerable positive employment and earnings effects. ${ }^{1}$ The papers mentioned above based on administrative data usually exclude start-up subsidies from the analysis, since the administrative data only includes information on employment which is subject to social security contributions. Since this is not the case for self-employment, administrative data does not allow to draw conclusions about employment or earnings effects for self-employed individuals.

The contribution of this paper is as follows: we evaluate the effectiveness of both start-up programs in East Germany. Since the major goal of German ALMP is to avoid future unemployment and integrate unemployed individuals into the primary labor market, we concentrate on the outcome variables 'not unemployed' and 'in paid or self-employment'. In addition, we analyze the program's effects on personal income. We compare the labor market outcomes of the formerly unemployed entrepreneurs with other unemployed individuals (and not with other business start-ups). This approach is driven by the consideration that start-up subsidies form one component of ALMP, and their effectiveness should thus be compared to other ALMP programs. We base our analysis on a combination of administrative data from the FEA and a follow-up survey, containing approximately 1,300 participants in both programs who founded a business in the third quarter of 2003 in East Germany. The interviews took place at the beginning of 2005 and 2006, so that we observe individuals for at least 28 months after programs have started. While this means we can monitor the employment paths of individuals for at least 22 months after the program has ended for the BA, SUS was still going on at the end of our observation period. At this stage, participants in SUS were in their third year of participation and were receiving a reduced transfer payment. Hence, results for this program are only preliminary and interpretation hinges on this drawback. Additionally, we have a group of unemployed individuals (approx. 950) who were eligible for either program but

\footnotetext{
${ }^{1}$ Caliendo and Steiner (2007) additionally show, that these programs are also monetary efficient (from the viewpoint of the Federal Employment Agency).
} 
did not choose to participate in the third quarter of 2003. This nonparticipant group will function as our comparison group.

Given this informative data set, we base our analysis on the conditional independence assumption and use kernel matching estimators to estimate the treatment effects. To test the sensitivity of the results with respect to unobserved differences we also use a conditional difference-in-differences strategy as suggested by Heckman, Ichimura, Smith, and Todd (1998). The results show that at the end of our observation period both programs are effective in terms of the above-mentioned outcome variables. Unemployment rates of participants are lower, and employment rates and personal income are higher when compared to nonparticipants. Hence, this is first evidence that this relatively new ALMP instrument might work even in a labor market with structural problems such as the one in East Germany. Additionally, we present first descriptive evidence on the additional employment effects trough direct job creation. We find quite significant effects (e.g., $28 \%$ of the males have already at least one employee) for BA, whereas the effects are negligible for participants in the SUS.

The paper proceeds as follows. Section 2 briefly summarizes some facts about the East German labor market, focusing on self-employment, unemployment, and active labor market policies. Section 3 outlines our evaluation approach, while Section 4 describes the data used for the analysis. In Section 5 we discuss some implementation issues, Section 6 contains the results and, finally, Section 7 concludes.

\section{Unemployment, Self-Employment and Start-Up Subsidies in East Germany}

Table 1 contains some summary statistics of the East German labor market. It can be seen that the self-employment rate has steadily increased from 8\% in 1994 to around $11 \%$ in 2004, reaching the same level as West Germany. On the other hand, the unemployment rate is persistently high, fluctuating around $20 \%$ and $22 \%$ after 2000 . To overcome this unemployment problem, the German government spends significant amounts on ALMP (approximately $€ 8$ billion in East Germany in 2004) including measures like vocational training programs, job-creation schemes, employment subsidies, and subsidized self-employment of formerly unemployed individuals.

INSERT TABLE 1 ABOUT HERE 
Until 2003 the bridging allowance was the only program providing support to unemployed individuals who wanted to start their own business. Its main goal is to cover basic costs of living and social security contributions during the initial stage of self-employment. BA supports the first six months of self-employment by providing the same amount that the recipient of a BA would have received if he or she had remained unemployed. Since the unemployment scheme also covers social security contributions (including health insurance, retirement insurance, etc.) a lump sum for social security is granted, equal to $68.5 \%$ of the unemployment support that would have been received in 2003. Unemployed people are entitled to BA conditional on their business plan being approved externally, usually by the regional chamber of commerce. Thus, approval of an individual's application does not depend on the case manager at the local labor office.

In January 2003, an additional program was introduced to support unemployed people in starting a new business. This 'start-up subsidy' was introduced as part of a large package of ALMP programs introduced through the 'Hartz reforms'. ${ }^{2}$ The main goal of SUS is to secure the initial phase of self-employment. It focuses on the provision of social security to the newly self-employed person. The support is a lump sum of $€ 600 /$ month in the first year. A growth barrier is implemented in SUS such that the support is only granted if income does not exceed $€ 25,000$ per year. The support shrinks to $€ 360 /$ month in the second year and $€ 240 /$ month in the third. In contrast to the BA, SUS recipients are obligated to pay into the statutory pension insurance fund and may claim a reduced rate for statutory health insurance (Koch and Wießner, 2003). When the SUS was introduced in 2003, applicants did not have to submit business plans for prior approval, but have been required to do so since November 2004, as was already the case with the BA. See Table 2 for more details on both programs. In this institutional framework, rational program choice favors a BA if the unemployment benefits are fairly high and/or if the income generated through the start-up firm is expected to exceed $€ 25,000$. Both programs were replaced in August 2006 by a single new program - the new start-up subsidy program (Gründungszuschuss) — which will not be analyzed here. ${ }^{3}$

\section{INSERT TABLE 2 ABOUT HERE}

Hence, for a period of nearly four years, unemployed individuals could choose between two programs to help them start their own business. Table 1 contains some infor-

\footnotetext{
${ }^{2}$ See Caliendo and Steiner (2005) for an overview of the most relevant elements of the 'Harts reforms'.

${ }^{3}$ See Caliendo and Kritikos (2007a) for information and a critical discussion of the features of the new program.
} 
mation on participants and spending in measures promoting self-employment from 1995 to 2004. In 1995, about $2.3 \%$ of all unemployed individuals in East Germany participated in BA, and the FEA spent 1.1\% of their total resources for ALMP on BA. Numbers remained relatively constant until 2003 when the second program was introduced. In the first year following its introduction, nearly 30,000 individuals made use of the SUS. Table 1 also shows that the introduction of the SUS did not replace the BA but made self-employment significantly more attractive for the unemployed (BA entries increased by roughly $12 \%) .{ }^{4}$ In 2004 , as much as $6.5 \%$ of East Germany's unemployed participated in these two programs, absorbing a share of $9 \%$ of the total spending on ALMP.

\section{$3 \quad$ Identifying Average Treatment Effects}

We base our analysis on the potential outcome framework, also known as the Roy(1951)Rubin(1974) model. The two potential outcomes are $Y^{1}$ (individual receives treatment, $D=1$ ) and $Y^{0}$ (individual does not receive treatment, $D=0$ ). The actually observed outcome for any individual $i$ can be written as: $Y_{i}=Y_{i}^{1} \cdot D_{i}+\left(1-D_{i}\right) \cdot Y_{i}^{0}$. The treatment effect for each individual $i$ is then defined as the difference between her potential outcomes: $\tau_{i}=Y_{i}^{1}-Y_{i}^{0}$. Since we can never observe both potential outcomes for the same individual at the same time, the fundamental evaluation problem arises. We will focus on the most prominent evaluation parameter, which is the average treatment effect on the treated (ATT), and is given by:

$$
\tau_{A T T}=E\left(Y^{1} \mid D=1\right)-E\left(Y^{0} \mid D=1\right) .
$$

Given equation (1), the problem of selection bias can be straightforwardly seen since the second term on the right hand side is unobservable. It describes the hypothetical outcome without treatment for those individuals who received treatment. Since with non-experimental data the condition $E\left(Y^{0} \mid D=1\right)=E\left(Y^{0} \mid D=0\right)$ is usually not satisfied, estimating ATT by the difference in sub-population means of participants $E\left(Y^{1} \mid D=1\right)$ and non-participants $E\left(Y^{0} \mid D=0\right)$ will lead to a selection bias. This bias arises because participants and non-participants are selected groups that would have different outcomes, even in absence of the program, and might be caused by observable or unobservable factors. ${ }^{5}$ We will combine two evaluation methods-matching and difference-in-differences - to cover both possible sources of selection bias.

\footnotetext{
${ }^{4}$ Caliendo and Kritikos (2007b) discuss in detail not only the characteristics of the new entrepreneurs but also those of the created businesses.

${ }^{5}$ See, e.g., Caliendo and Hujer (2006) for further discussion.
} 


\subsection{Matching under Unconfoundedness}

Matching is based on the conditional independence (or unconfoundedness) assumption, which states that conditional on some covariates $W=(X, Z)$, the potential outcomes $\left(Y^{1}, Y^{0}\right)$ are independent of $D .{ }^{6}$ Since we are interested in ATT only, we only need to assume that $Y^{0}$ is independent of $D$, because the moments of the distribution of $Y^{1}$ for the treatment group can be directly estimated. That is:

\section{Assumption 1 Unconfoundedness for Comparison Group: $\quad Y^{0} \amalg D \mid W$,}

where $\amalg$ denotes independence. Clearly, this assumption may be a very strong one and has to be justified on a case-by-case basis, since the researcher needs to observe all variables that simultaneously influence participation and outcomes. We will do so in Section 5.1. Additionally, it has to be assumed that:

Assumption 2 Weak Overlap: $\operatorname{Pr}(D=1 \mid W)<1$,

for all $W$. This implies that there is a positive probability for all $W$ of not participating, i.e., that there are no perfect predictors which determine participation. These assumptions are sufficient for identification of the ATT, which can be written as:

$$
\tau_{A T T}^{M A T}=E\left(Y^{1} \mid W, D=1\right)-E_{W}\left[E\left(Y^{0} \mid W, D=0\right) \mid D=1\right]
$$

where the first term can be estimated from the treatment group and the second term from the mean outcomes of the matched comparison group. The outer expectation is taken over the distribution of $W$ in the treatment group.

As matching on $W$ can become hazardous when $W$ is of high dimension ('curse of dimensionality'), Rosenbaum and Rubin (1983) suggest the use of balancing scores $b(W)$. These are functions of the relevant observed covariates $W$ such that the conditional distribution of $W$ given $b(W)$ is independent of the assignment to treatment, that is, $W \amalg D \mid b(W)$. The propensity score $P(W)$, i.e., the probability of participating in a program, is one possible balancing score. For participants and nonparticipants with the same balancing score, the distributions of the covariates $W$ are the same, i.e., they are balanced across the groups. Hence, assumption 1 can be re-written as $Y^{0} \amalg D \mid P(W)$ and the new overlap condition is given by $\operatorname{Pr}(D=1 \mid P(W))<1$.

\footnotetext{
${ }^{6}$ See Imbens (2004) or Smith and Todd (2005) for recent overviews regarding matching methods.
} 


\subsection{Combining Matching with Difference-in-Differences}

Even though we will argue in Section 5.1 that the CIA is most likely to hold in our setting, we will test the sensitivity of our results with respect to unobserved heterogeneity. The matching estimator described so far assumes that after conditioning on a set of observable characteristics, (mean) outcomes are independent of program participation. The conditional DID or DID matching estimator relaxes this assumption and allows for unobservable but temporally invariant differences in outcomes between participants and nonparticipants. This is achieved by comparing the conditional before/after outcomes of participants with those of nonparticipants. DID matching was first suggested by Heckman et al. (1998). It extends the conventional DID estimator by defining outcomes conditional on the propensity score and using semiparametric methods to construct the differences. Therefore, it is superior to DID as it does not impose linear functional form restrictions in estimating the conditional expectations of the outcome variable, and it re-weights the observations according to the weighting function of the matching estimator (Smith and Todd, 2005). If the parameter of interest is ATT, the DID propensity score matching estimator is based on the following identifying assumption:

$$
E\left[Y_{t}^{0}-Y_{t^{\prime}}^{0} \mid P(W), D=1\right]=E\left[Y_{t}^{0}-Y_{t^{\prime}}^{0} \mid P(W), D=0\right]
$$

where $(t)$ is the post-treatment and $\left(t^{\prime}\right)$ the pre-treatment period. It also requires the common support condition to hold and can be written as:

$$
\tau_{A T T}^{C D I D}=E\left(Y_{t}^{1}-Y_{t^{\prime}}^{0} \mid P(W), D=1\right)-E\left(Y_{t}^{0}-Y_{t^{\prime}}^{0} \mid P(W), D=0\right) .
$$

\section{Data and Some Descriptives}

We use a unique data set which combines administrative data from the FEA with survey data. ${ }^{7}$ For the administrative part we use data based on the 'Integrated Labor Market Biographies' (ILMB, Integrierte Erwerbs-Biographien) of the FEA, containing relevant register data from four sources: employment history, unemployment support receipt, participation in active labor market measures, and job seeker history. Since the administrative data are only available with a certain time lag and more importantly, do not provide any information on the employment status and/or income of self-employed individuals, we en-

\footnotetext{
${ }^{7}$ The data was gathered within a research project for the Federal Ministry of Labor (see Forschungsverbund IAB, DIW, SINUS, GfA, infas, 2006, for details).
} 
riched the ILMB data with information from a computer-assisted telephone interview. To do so, we randomly drew participants from each program who became self-employed in the third quarter of 2003. Since we wanted to compare them with nonparticipants, we had to choose a comparison group. Choosing such a group is a heavily discussed topic in the recent evaluation literature. Although participation in ALMP programs is not mandatory in Germany, the majority of unemployed persons participate at some point in time. Thus, comparing participants to individuals who never participate is inadequate, since it can be assumed that the latter group is particularly selective. ${ }^{8}$ Sianesi (2004) discusses this problem for Sweden and argues that those who never participate did not enter a program because they had already found a job. Additionally, since we did not know the future employment/participation status of the comparison group before the interviews took place, we restricted this comparison group to those who were unemployed in the third quarter of 2003, eligible for participation in either of the two programs, but did not join a program in this quarter. What should be kept in mind is that these comparison group members might participate in some ALMP program after this quarter. ${ }^{9}$

To minimise the survey costs we used a crude propensity score matching approach to select somewhat similar unemployed individuals. ${ }^{10}$ These individuals were interviewed twice. The first interview took place in January/February 2005 and the second in January/February 2006. This enables us to observe the labor market activity of individuals for at least 28 months after programs started. We compiled a sample of 1,297 individuals who had started a new business out of unemployment. Of these, 647 individuals received a SUS and 650 received BA. Additionally, a control group of 943 nonparticipants was assembled.

A full list of the available variables can be found in Table A.1 in the Appendix; Table 3 contains sample means of the most relevant ones. What should be kept in mind is the non-random sample of nonparticipants. Since we used a crude matching approach to make individuals similar, the nonparticipant sample does not represent a random sample of unemployed individuals. Clearly, this does not affect our estimation and interpretation

\footnotetext{
${ }^{8}$ Furthermore, it should be noted that using individuals who are observed to never participate in the programs as the comparison group may invalidate the conditional independence assumption due to conditioning on future outcomes (see discussion in Fredriksson and Johansson, 2007).

${ }^{9}$ The actual number of nonparticipants who participated in any ALMP program after this quarter is rather low. It is approximately $5 \%$ after $12,7 \%$ after 18 and around $10 \%$ after 24 months.

${ }^{10}$ The potential comparison group consisted of roughly 330,000 individuals. Control individuals (for the interview) were chosen to resemble the distribution of some key variables-including gender, region, age, previous unemployment duration, qualification, and nationality - in the population of the treated individuals. To do so, we estimated a 'crude propensity score' based on these variables and chose for every participant nonparticipants with a similar propensity score as interviewees.
} 
strategy but should be kept in mind when interpreting the differences.

INSERT TABLE 3 ABOUT HERE

A first glance at the number of observations reveals clear gender differences in participation in both programs. Whereas the male-female ratio is about 2.2:1 for BA, it is only 1.3:1 for the SUS. Further differences arise when looking at qualifications. In general it can be stated that participants in SUS are less qualified (when compared to BA participants). This is true for the comparison of the participants' qualifications either by highest school-leaving degree or the variable 'job qualifications', an assessment by the placement officer in the local labor office. Based on that, it is hardly surprising that participants in BA programs also have a more favorable labor market history. Not only were they less frequently found among the long-term unemployed before starting a program they also had higher and longer claims for unemployment benefits. We will discuss the available variables in more detail in the next section, where we also discuss the validity of the CIA.

\section{$5 \quad$ Implementing the Estimators}

Having discussed our evaluation approach in the previous section, we now present details on the implementation of the propensity score matching estimator. Caliendo and Kopeinig (2008) provide an extensive overview of the issues arising when implementing matching estimators. They point out that a crucial step is to discuss the likely validity of the underlying CIA. Hence, we deal with this issue in Section 5.1. This will be followed by the estimation of the propensity score and a discussion of matching details in 5.2.

\subsection{Validity of the CIA and Propensity Score Estimation}

The CIA is in general a very strong assumption and the applicability of the matching estimator depends crucially on its plausibility. Blundell, Dearden, and Sianesi (2005) argue that the plausibility of such an assumption should always be discussed on a caseby-case basis. Only variables that influence the participation decision and the outcome variable simultaneously should be included in the matching procedure. Hence, economic theory, a sound knowledge of previous research and information about the institutional setting should guide the researcher in specifying the model (see, e.g., Smith and Todd, 2005 or Sianesi, 2004). 
Both economic theory and previous empirical evaluation studies highlight the importance of socio-demographic and qualificational variables. Regarding the first category we can use variables such as age, marital status, number of children, nationality (German or foreigner), and health restrictions. Additionally, we also use information whether individuals want to work full-time or part-time, and hence we might be able to approximate the labor market flexibility of these individuals. A second class of variables (qualification variables) refers to the human capital of the individual, which is also a crucially important determinant of labor market prospects. The attributes available are school degree, job qualification, and work experience. Furthermore, previous evaluation studies also point out that unemployment dynamics and labor market history play a major role in driving outcomes and program participation. Hence, we use career variables describing the individual's labor market history. The available data in this regard is quite extensive (inter alia: nearly complete seven-year labor market history; daily earnings from employment; amount of daily unemployment benefits; duration of last unemployment spell, employment status before unemployment, previous profession, etc.). Heckman et al. (1998) also emphasize the importance of drawing treatment and comparison groups from the same local labor market and giving them the same questionnaire, where the latter is ensured in our data. To account for the situation on the local labor market, we use a classification of similar and comparable labor office districts derived by the FEA (see Blien et. al, 2004, for details). Finally, the institutional structure and the selection process into programs provide further guidance in selecting the relevant variables. As we have seen from the discussion in Section 2, the two programs differ, among other things, in the size of the subsidy. Whereas the SUS is a lump sum, the BA depends on the amount of the unemployment benefits. Hence, we include the daily unemployment transfer payment before the start of the program as an explanatory variable. In contrast to many other studies, we are also able to include the remaining duration of unemployment benefits, which probably plays a determining role in these individuals' decision. ${ }^{11}$

Based on this exhaustive data, we argue that the CIA holds in our application. The set of variables is extensive and covers nearly all variables which have been identified to be important in previous evaluation studies of labor market policies. However, it should also be clear that some variables which might influence self-employment dynamics are absent in our data (see Georgellis, Sessions, and Tsisianis, 2005, for a recent overview). Even though one might argue that these variables, e.g., intergenerational links, are less important in

\footnotetext{
${ }^{11}$ Lechner and Wunsch (2006) evaluate the effectiveness of ALMP (excluding start-up subsidies) in East Germany using a very similar set of variables.
} 
our context (since we compare participants with other unemployed individuals), we test the sensitivity of the results with respect to time-invariant unobserved differences between participants and nonparticipants.

\subsection{Propensity Score Estimation and Matching Details}

Since the choice probabilities are not known a priori, we have to replace them with an estimate. To do so, we estimate binary conditional probabilities for both programs versus nonparticipation. Since we estimate the effects separately for men and women, we are left with four logit estimations. The results can be found in Table A.1 in the Appendix. To ensure the comparability between the estimates, we choose the same covariates for each combination and both genders. We do not interpret the results of the propensity score estimation since we only use this estimation to reduce the dimensionality problem and the group of participants and nonparticipants are already quite similar due to the construction of the data.

\section{InSERT Figure 1 ABOUt HERE}

The distribution of the propensity score is depicted in Figure 1. A visual analysis already suggests that the overlap between the group of participants and nonparticipants is sufficient in general. Nevertheless, there are some parts of the distribution (starting approximately at a propensity score value of 0.7 ) where the mass of comparison individuals is quite thin. This is especially true for female participants in BA. However, by using the usual 'Minmax' criterion, where treated individuals are excluded from the sample whose propensity score lies above the highest propensity score in the comparison group, only 26 individuals are dropped overall. ${ }^{12}$

Several matching procedures have been suggested in the literature, such as nearestneighbor or kernel matching. ${ }^{13}$ To introduce them, a more general notation is needed: let $I_{0}$ and $I_{1}$ denote the set of indices for nonparticipants and participants. We estimate the effect of treatment for each treated observation $i \in I_{1}$ in the treatment group by contrasting her outcome with treatment with a weighted average of control group observations $j \in I_{0}$

\footnotetext{
${ }^{12} \mathrm{We}$ also test the sensitivity of the results with respect to a stricter imposition of the common support requirement, e.g., by dropping $5 \%(10 \%)$ of the individuals where the overlap between participants and nonparticipants is especially low. It turns out that the results are not sensitive.

${ }^{13}$ See Heckman et al. (1998), Smith and Todd (2005), and Imbens (2004) for overviews.
} 
in the following way:

$$
\Delta^{M A T}=\frac{1}{N_{1}} \sum_{i \in I_{1}}\left[Y_{i}^{1}-\sum_{j \in I_{0}} \omega_{N_{0}}(i, j) Y_{j}^{0}\right]
$$

where $N_{0}$ is the number of observations in the control group $I_{0}$ and $N_{1}$ is the number of observations in the treatment group $I_{1}$. Matching estimators differ in the weights attached to the members of the comparison group, where $\omega_{N_{0}}(i, j)$ is the weight placed on the $j$-th individual from the comparison group in constructing the counterfactual for the $i$-th individual of the treatment group (Heckman et al., 1998). For example, with nearest-neighbor matching, only the closest neighbor is used to construct the counterfactual outcome, while kernel matching (KM) is a non-parametric estimator that uses (nearly) all units in the control group. One major advantage of KM is the lower variance which is achieved because more information is used for constructing counterfactual outcomes. Since our treatment and comparison groups are rather small, we will focus on this method in the later empirical application. ${ }^{14}$ An additional advantage of kernel matching comes from the results of Heckman, Ichimura, and Todd (1998) who derive the asymptotic distribution of these estimators and show that bootstrapping is valid to draw inference for this matching method. This allows us to circumvent the issues raised by Abadie and Imbens (2006), pointing out that bootstrap methods are invalid for NN matching.

Before applying kernel matching, assumptions have to be made regarding the choice of the kernel function and the bandwidth parameter $h$. The choice of the kernel appears to be relatively unimportant in practice (see, e.g., Jones, Marron, and Sheather (1996), Pagan and Ullah (1999), or DiNardo and Tobias (2001)). What is seen as more important is the choice of the bandwidth parameter $h$ with the following trade-off arising: high values of $h$ yield a smoother estimated density function, producing a better fit and a decreasing variance between the estimated and the true underlying density function. On the other hand, underlying features may be smoothed away by a large $h$, leading to a biased estimate. The choice of $h$ is therefore a compromise between a small variance and an unbiased estimate of the true density function. Instead of using a 'rule of thumb' as proposed by Silverman (1986), we use 'leave-one-out' cross-validation (CV) as suggested in Black and Smith (2004) and Galdo (2005) to choose $h$. More details and most importantly, the chosen bandwidth parameters can be found in Table A.2 in the Appendix. We will

\footnotetext{
${ }^{14}$ Additional sensitivity analysis reveals that our results are not sensitive to the matching algorithm chosen. Results are available from the author on request.
} 
use these bandwidth parameters for the further empirical analysis. ${ }^{15}$

To test if the matching procedure is able to balance all the covariates we ran a standardized difference (SD) test (Rosenbaum and Rubin, 1985). This is a suitable indicator to assess the distance in marginal distributions of the $W$-variables. For each covariate $W$ it is defined as the difference of sample means in the treated and matched control subsamples as a percentage of the square root of the average of sample variances in both groups. This is a common approach used in many evaluation studies, including those by Lechner (1999), Sianesi (2004) and Caliendo et al. (2007). Table 4 shows the mean standardized difference (MSD), i.e., the mean of the SD over all covariates before and after the matching took place.

\section{INSERT TABLE 4 ABOUT HERE}

It can be seen that the MSD before matching lies between $7.4 \%$ for women and $9.2 \%$ for men in SUS and even between 15.1\% (men) and 19.4\% (women) in BA. The matching procedure is able to balance the distribution of the covariates very well. The MSD after matching lies below 5\% for all the subgroups. Additionally, Sianesi (2004) suggests reestimating the propensity score on the matched sample (i.e., on the participants and matched nonparticipants) and comparing the pseudo- $R^{2}$ 's before and after matching. After matching there should be no systematic differences in the distribution of the covariates between the two groups. Therefore, the pseudo- $R^{2}$ after matching should be fairly low. As the results from Table 4 show, this is true for our estimation. The results of the $F$-tests point in the same direction, indicating a joint significance of all regressors before but not after matching. Overall, these are satisfying results and show that the matching procedure was successful in balancing the covariates between treated individuals and members from the comparison group. Hence, we move on to the presentation of the results.

\section{Results}

We discuss the effectiveness of the two programs in relation to nonparticipation based on three outcome variables: first, we want to know if program participation lowers the risk of returning to unemployment. To this end, we construct a variable that treats registered unemployment as a failure and all possible other states as a success (outcome variable A). Since avoiding unemployment is one of the two major goals of German ALMP, this

\footnotetext{
${ }^{15}$ Estimations are done using the PSMATCH2 Stata ado-package by Leuven and Sianesi (2003).
} 
allows us to analyze the effectiveness of the programs in reaching this goal. A second aim is integration into regular, stable employment. Hence, we construct a second outcome variable which treats ongoing self-employment and regular paid employment as a success (outcome variable B). Finally, we also assess the effects of the programs on the personal income of participants. We start the discussion with the employment effects over time, before we present cumulated effects and income effects. For the latter two, we also present conditional difference-in-differences results to test the sensitivity.

Effects on the Employment Status over Time: Figure 2 presents the treatment effects over time, where the upper panel relates to outcome variable A (not unemployed) and the lower part to outcome variable B (self-employed or in regular employment). Effects for men (women) are depicted on the left (right) side of each row. Rows 1 and 3 show the effects of participating in SUS vs. nonparticipation, whereas rows 2 and 4 show the effects of BA.

Effects start in the first month after the treatment has begun. Before starting the interpretation, one has to note the following: a look at both figures shows a strong positive effect at the beginning of our observation period. This can be seen as a 'positive locking-in effect'. Whereas a locking-in effect usually corresponds to a negative effect during participation in a program - for example, vocational training - the findings for our programs are the opposite. Both participants and nonparticipants are unemployed in the month before the treatment starts, then participants join the program and change immediately to the 'hoped-for' state. That is, they leave unemployment and become selfemployed, which is viewed as a success for both outcome variables. Hence, one should not overemphasize this large effect at the start of the self-employment spell. BA runs out after six months, and a reasonable interpretation should start there. Clearly, for the three-year-long SUS, the problem is that participants may receive aid during the complete observation period, interfering with interpretation. However, after 12 months, the transfer payment is reduced from $€ 600$ to $€ 360$ and after 24 months it is further reduced to $€ 240$. Since this reduced payment is hardly sufficient to cover social security contributions, it gives us an initial idea of the success of the newly self-employed.

\section{InSERT Figure 2 ABOUt HERE}

Let us start the discussion with outcome variable A. In the first months after treatment starts, we have very high positive effects for both programs, lying well above 60 percentage points, irrespective of program and gender. This means, for example, that 
the unemployment probability of participants in SUS or BA is about 60 percentage points lower than the unemployment probability of nonparticipants. Clearly, results at that point have to be interpreted with care since both programs are still going on. The effects show a negative time trend, where the paths of the programs are very similar up to month six. After that, the transfer payment for participants in BA terminates and the effects plunge. The downward trend continues but the rate of decrease is much lower. At the end of our observation period, that is, 28 months after programs have started, we get an effect of approximately 28 percentage points for male and 23 percentage points for female participants in BA. If we look at the effect of SUS versus nonparticipation, the downward trend is much smoother, spiking somewhat in month 12 , but decreasing relatively constantly to an effect of 34 percentage points for males and 44 percentage points for females in month $28 .{ }^{16}$ A similar pattern — but on a higher level — can be found for outcome variable B (see lower part of Figure 2). This is a strong indication that both programs are not only effective in avoiding unemployment but that they also give individuals much higher chances of remaining employed (either in paid or self-employment). The differences in both outcome variables can be explained by the fact that outcome variable A only treats registered unemployment as a failure. When individuals retreat from the labor market - and this might be especially relevant for women - they are not counted as a failure. Hence, the second outcome variable, only treating individuals as a success if they are in employment, has more explanatory power.

Cumulated Effects: Table 5 contains the cumulative effects over time, i.e., the cumulative monthly effects over the observation period. For the outcome variable 'not unemployed' this shows the difference in months spent in unemployment between participants and nonparticipants. It can be seen that male participants in SUS spend roughly 13.9 months less in unemployment than nonparticipants. For female participants in SUS the effect is approximately 16.4 months. The cumulative effect for participants in BA is slightly lower, at 11.6 months for men and 11.1 months for women. We have already discussed that the effects for the outcome variable 'self-employment or paid employment' are even higher, which is also reflected by the cumulative effects of around 15.5 (19.0) months for men (women) in SUS and 13.2 (13.8) months for men (women) in BA.

\footnotetext{
${ }^{16}$ The dip in the effects, especially for men, between months 16 and 20 is caused by a change in the interview information. Individuals were interviewed twice, in 2005 and 2006 . Months 16 to 20 might involve a time overlap between the first and second interview and might be prone to recall errors. Hence, information for these months should be interpreted with care. For the overall interpretation, especially when moving towards the end of the observation period, this should not pose any problems.
} 
As outlined in Section 3.2, we also tested the sensitivity of our results with respect to time-invariant unobserved heterogeneity by using a conditional difference-in-differences approach. Before using such an approach, one has to determine the reference level for the before/after difference. We choose three different time periods for the comparison. In the first approach we use the time period from 1997 to 2002, that is, the six-year employment history before entering the program. For the first outcome variable, we sum the months not spent in unemployment, whereas for the second, we sum the months spent in paid employment. Additionally, we restrict the reference period to the latest three years (2000-2002) as well as the earliest three years (1997-1999).

Looking at the table, we see that the results are remarkably stable. For example, the effect on outcome variable B for men in SUS was 13.9 months with the matching approach and varies between 13.9 and 14.1 months with the CDID approaches. For the other groups the variation is similar and shows that additionally controlling for possible unobserved differences between participants and nonparticipants did not add much information for our estimates. This can be seen as evidence of the validity of the CIA in our context. Even when looking at outcome variable B, the variation is still negligible.

Effects on Personal Income: After having established that participants in both programs are more likely to be employed and less likely to be unemployed than nonparticipants, we now investigate whether participants also earn more money. We use two income-related outcome variables: the more relevant one is monthly income from selfemployment or paid employment (labor income). However, since it is often argued that differences between (low) labor income and unemployment benefits are especially low in Germany, we will also look at the total personal income of individuals, that is, including support such as unemployment benefits.

\section{INSERT TABLE 6 ABOUT HERE}

Table 6 contains the results for both outcome variables. Once again, we first present the results from matching estimates before presenting CDID results. ${ }^{17}$ It is quite striking that all participants have higher incomes than nonparticipants for both possible outcome variables. However, for females some of the differences are not significant. The upper half

\footnotetext{
${ }^{17}$ For the DID procedure we use three reference levels: 1) The monthly unemployment benefits before the program started, 2) the average monthly income in 2002 and 3) the average monthly income from regular employment in 2002 .
} 
of Table 6 reveals that male participants in SUS earn around $€ 600$ per month more than their counterparts in the comparison group. Once again, the CDID does not add much information to the matching estimates since all estimates range between $€ 620$ and $€ 690$. For female participants, the effect is much lower (around $€ 320$ ) but still significant. The effects for the participants in BA is even higher. Male participants earn about $€ 820$ more per month. For females, the effect, with $€ 290$, is comparable to the effect for the SUS participants. Hence, we can conclude that participating in either of the two programs has helped individuals to earn more money at the end of our observation period. For males this finding remains unaffected even if we use the total personal income of individuals as an outcome variable, where we additionally take unemployment benefits and other public transfers into account. For females, however, looking at this outcome variable reveals that there are no significant differences in the total income of female participants and nonparticipants.

Direct Employment Effects - Descriptive Evidence: Policy makers usually hope for a second positive effect when subsidizing start-ups: additional employment effects through direct job-creation. Even though the effects of these policies on (overall) employment cannot be judged by microeconometric analysis (since macroeconomic effects would have to be taken into account), we want to present some descriptive evidence on the extent of these potential effects.

\section{INSERT TABLE 7 ABOUT HERE}

Table 7 contains information on the share of start-ups which have employees 28 months after the programs started as well as the number of employees. Two findings are striking: first, participants in BA are at this point in time more likely to have employees. Second, it is rather unlikely that the businesses created with the start-up subsidy will generate considerable additional employment in the future. To be more specific: $28 \%$ $(22 \%)$ of the male (female) participants in BA already have at least one employee at the time of the second interview, whereas this is true for only $8-9 \%$ of the participants in SUS. Male participants in BA not only have the most employees (around 4) but also the highest share of regular employees (around 56\%). Clearly, these numbers do not allow to draw conclusions about the relative effectiveness of the two start-up subsidies since the businesses started differ in a variety of aspects (e.g., start-up capital, industry, etc.). Looking at the lower part of Table 7 shows that participants who have no employees yet are also reluctant concerning the prospect of employing someone in the future. This is 
especially the case for the participants in SUS. Being asked whether they would like to employ further persons in the future, $50 \%(37 \%)$ of the females (males) answered 'No, by no means' and 34\% (36\%) 'Rather no'. Hence, it is rather unlikely that these businesses will create significant additional employment in the future.

\section{Conclusion}

The aim of this paper has been to evaluate two active labor market programs in East Germany for which no empirical evidence on their effectiveness had been gathered so far. In light of the rather disappointing performance of other programs in East Germanyincluding training programs, wage subsidies and job-creation schemes - our findings are rather promising, showing that these programs designed to encourage unemployed people to become self-employed might have the potential not only to combat East Germany's problem of persistently high unemployment, but also to increase its low (self-)employment rate.

Our analysis is based on a dataset that combines administrative with survey data and allows us to follow the employment paths of individuals for a period of 28 months after the programs have started. For the first program under consideration - the bridging allowance - we observed participants for 22 months after the program ended. However, participants in the second program - the start-up subsidy - are in their third year of participation at the end of our observation period and mostly still receive further support (although at a reduced rate). Therefore, the results for SUS have to be treated as preliminary. Given the relatively stable participant structure in the BA program since the introduction of the SUS, one can argue that the SUS attracts a different 'clientele' for self-employment. In general it can be stated that participants in SUS are less qualified (when compared to BA participants) and that this program is more frequently used by women.

We have evaluated the effectiveness of both programs relative to nonparticipation. To this end we used a kernel matching estimator and a conditional difference-anddifferences estimator. Three outcome variables were of major interest. The first was 'not unemployed', corresponding to one of the main aims of the FEA. The second one combines the two possible labor market states 'in self-employment' and 'in paid employment' into one success criterion. The results indicate that both programs are successful: at the end of our observation period, the unemployment rate of participants in BA was approximately 25 percentage points lower than that of nonparticipants, and for participants in SUS it 
was around 34 percentage points lower for men and as much as 44 percentage points lower for women. Additionally, both the probability of being in self-employment and/or paid employment and the personal income are significantly higher for participants, even though the income effects for women are not always significant.

This is one of the first studies that allows inferences to be drawn about the effectiveness of start-up programs in East Germany. Most previous studies on the effectiveness of ALMP in the eastern part of Germany neglected these programs since the used administrative data does not contain information on employment (or earnings) of self-employed individuals. In contrast to the other programs that have been evaluated recently (including job-creation schemes and vocational training programs), we find considerable positive effects for start-up subsidies. Hence, programs aimed at turning the unemployed into entrepreneurs may be a promising strategy in East Germany.

To allow more precise policy recommendations, further research is needed. First of all, the observation period for the start-up subsidy is still quite short and should be extended. This will be especially important to judge the income effects for women, which are already partly not significant at the moment. Second, the relative effects of both programs should be estimated, which would allow their respective designs to be judged as well as their suitability for different target groups. Additionally, it would be of interest to look at the development of the start-ups in terms of turnover and number of jobs directly created. Such an investigation would also enable an extensive cost-benefit analysis taking direct (and indirect) costs and benefits into account. 


\section{References}

Abadie, A. and G. Imbens (2006). On the Failure of the Bootstrap for Matching Estimators. Working Paper, Harvard University.

Baumgartner, H. and M. Caliendo (2007). Turning Unemployment into Self-Employment: Effectiveness of Two Start-Up Programmes. IZA Discussion Paper No. 2660, forthcoming in: Oxford Bulletin of Economics and Statistics.

Biewen, M., B. Fitzenberger, A. Osikominu, and M. Waller (2007). Which Program for Whom? Evidence on the Comparative Effectiveness of Public Sponsored Training Programs in Germany. Discussion Paper 2885, IZA.

Black, D. and J. Smith (2004). How Robust is the Evidence on the Effects of the College Quality? Evidence from Matching. Journal of Econometrics 121(1), 99-124.

Blien, U., F. Hirschenauer, M. Arendt, H. J. Braun, D.-M. Gunst, S. Kilcioglu, H. Kleinschmidt, M. Musati, H. Roß, D. Vollkommer, and J. Wein (2004). Typisierung von Bezirken der Agenturen der Arbeit. Zeitschrift für Arbeitsmarktforschung 37(2), 146175.

Blundell, R., L. Dearden, and B. Sianesi (2005). Evaluating the Impact of Education on Earnings in the UK: Models, Methods and Results from the NCDS. Journal of the Royal Statistical Society, Series A 168(3), 473-512.

Bundesagentur für Arbeit (various issues). Arbeitsmarkt. Nürnberg.

Caliendo, M. and R. Hujer (2006). The Microeconometric Estimation of Treatment Effects - An Overview. Allgemeines Statistisches Archiv 90(1), 197-212.

Caliendo, M., R. Hujer, and S. Thomsen (2007). The Employment Effects of Job Creation Schemes in Germany - A Microeconometric Evaluation. IZA Discussion Paper No. 1512, forthcoming in: Advances in Econometrics, 21.

Caliendo, M. and S. Kopeinig (2008). Some Practical Guidance for the Implementation of Propensity Score Matching. Journal of Economic Surveys 22(1), 31-72.

Caliendo, M. and A. Kritikos (2007a). Die reformierte Existenzgründungsförderung für Arbeitslose: Chancen und Risiken. Discussion Paper 3114, IZA, Bonn.

Caliendo, M. and A. Kritikos (2007b). Start-Ups by the Unemployed: Characteristics, Survival and Direct Employment Effects. Discussion Paper 3220, IZA, Bonn.

Caliendo, M. and V. Steiner (2005). Aktive Arbeitsmarktpolitik in Deutschland: Bestandsaufnahme und Bewertung der mikroökonomischen Evaluationsergebnisse. Zeitschrift für Arbeitsmarktforschung / Journal for Labour Market Research 38(2-3), 396-418.

Caliendo, M. and V. Steiner (2007). The Monetary Efficiency of Start-Up Subsidies in Germany. Mimeo, Bonn/Berlin.

DiNardo, J. and J. Tobias (2001). Nonparametric Density and Regression Estimation. Journal of Economic Perspectives 15(4), 11-28.

Forschungsverbund IAB, DIW, SINUS, GfA, infas (2006). Evaluation der Maßnahmen zur Umsetzung der Vorschläge der Hartz-Kommission: Wirksamkeit der Instrumente: Existenzgründungen (Modul 1e). Berlin: Federal Ministry of Labor.

Fredriksson, P. and P. Johansson (2007). Dynamic Treatment Assignment - The Consequences for Evaluations Using Observational Data. Journal of Business and Economic Statistics. 
Galdo, J. (2005). Bandwidth Selection and the Estimation of Treatment Effects with Non-Experimental Data. Working paper, Syracuse University.

Georgellis, Y., J. Sessions, and N. Tsisianis (2005). Self-Employment Longitudinal Dynamics: A Review of the Literature. Discussion Paper, Brunel University.

Heckman, J., H. Ichimura, J. Smith, and P. Todd (1998). Characterizing Selection Bias Using Experimental Data. Econometrica 66(5), 1017-1098.

Heckman, J., H. Ichimura, and P. Todd (1998). Matching as an Econometric Evaluation Estimator. Review of Economic Studies 65(2), 261-294.

Imbens, G. (2004). Nonparametric Estimation of Average Treatment Effects under Exogeneity: A Review. The Review of Economics and Statistics 86(1), 4-29.

Jones, M., S. Marron, and S. Sheather (1996). A Brief Survey of Bandwidth Selection for Density Estimation. Journal of the American Statistical Association 91(433), 401-407.

Koch, S. and F. Wießner (2003). Wer die Wahl hat, hat die Qual. IAB Kurzbericht (2).

Lechner, M. (1999). Earnings and Employment Effects of Continuous Off-the-Job Training in East Germany After Unification. Journal of Business Economic Statistics 17(1), 7490 .

Lechner, M. and C. Wunsch (2006). Active Labour Market Policy in East Germany: Waiting for the Economy to Take Off. Discusssion Paper No. 2363, IZA, Bonn.

Leuven, E. and B. Sianesi (2003). PSMATCH2: Stata Module to Perform Full Mahalanobis and Propensity Score Matching, Common Support Graphing, and Covariate Imbalance Testing. Software, http://ideas.repec.org/c/boc/bocode/s432001.html.

Pagan, A. and A. Ullah (1999). Nonparametric Econometrics. Cambridge: Cambridge University Press.

Rosenbaum, P. and D. Rubin (1983). The Central Role of the Propensity Score in Observational Studies for Causal Effects. Biometrika 70(1), 41-50.

Rosenbaum, P. and D. Rubin (1985). Constructing a Control Group Using Multivariate Matched Sampling Methods that Incorporate the Propensity Score. The American Statistican 39(1), 33-38.

Roy, A. (1951). Some Thoughts on the Distribution of Earnings. Oxford Economic Papers 3(2), 135-145.

Rubin, D. (1974). Estimating Causal Effects to Treatments in Randomised and Nonrandomised Studies. Journal of Educational Psychology 66, 688-701.

Sianesi, B. (2004). An Evaluation of the Swedish System of Active Labour Market Programmes in the 1990s. The Review of Economics and Statistics 86(1), 133-155.

Silverman, B. (1986). Density Estimation for Statistics and Data Analysis. London: Chapman \& Hall.

Smith, J. and P. Todd (2005). Does Matching Overcome LaLonde's Critique of Nonexperimental Estimators? Journal of Econometrics 125(1-2), 305-353. 


\section{Tables and Figures}

Table 1: Self-employment, Unemployment and Start-Up Subsidies in East Germany, 1994-2004

\begin{tabular}{|c|c|c|c|c|c|c|c|c|c|}
\hline & 1994 & 1995 & 1998 & 1999 & 2000 & 2001 & 2002 & 2003 & 2004 \\
\hline Self-employed ${ }^{a}$ (in \%) & 8.0 & 8.1 & 8.8 & 8.9 & 9.2 & 9.6 & 9.9 & 10.4 & 11.0 \\
\hline Unemployed $^{a}$ (in \%) & 15.1 & 13.6 & 20.4 & 19.9 & 20.2 & 20.8 & 21.5 & 22.6 & 22.2 \\
\hline \multicolumn{10}{|l|}{ ALMP participants (Entries in thousand) } \\
\hline Vocational Training & - & - & 235.9 & 183.3 & 213.7 & 188.4 & 198.2 & 92.3 & 61.1 \\
\hline Job-Creation Schemes & - & - & 271.8 & 210.5 & 181.4 & 130.1 & 121.4 & 109.4 & 112.9 \\
\hline Bridging Allowance & 15.1 & 23.9 & 31.6 & 32.2 & 33.7 & 34.4 & 38.2 & 43.4 & 46.1 \\
\hline Start-Up Subsidy & - & - & - & - & - & - & - & 29.2 & 57.5 \\
\hline Sup. Self-Employment (total) & 15.1 & 23.9 & 31.6 & 32.2 & 33.7 & 34.4 & 38.2 & 72.6 & 103.6 \\
\hline Sup. Self-Employment ${ }^{b}$ (total in $\%$ ) & 1.3 & 2.3 & 2.1 & 2.2 & 2.2 & 2.2 & 2.5 & 4.5 & 6.5 \\
\hline \multicolumn{10}{|l|}{ ALMP expenditure (in bn Euro) } \\
\hline ALMP - Total & -.- & 10.19 & 10.28 & 11.41 & 9.77 & 10.12 & 10.25 & 8.92 & 7.63 \\
\hline Vocational Training & - & - & 2.79 & 2.78 & 2.75 & 2.79 & 2.88 & 1.97 & 1.28 \\
\hline Job-Creation Schemes & - & - & 2.79 & 2.89 & 2.67 & 2.11 & 1.78 & 1.31 & 0.96 \\
\hline Bridging Allowance $^{c}$ & 0.03 & 0.11 & 0.16 & 0.23 & 0.22 & 0.23 & 0.27 & 0.32 & 0.37 \\
\hline Start-Up Subsidy & - & - & - & - & - & - & - & 0.09 & 0.31 \\
\hline Sup. Self-Employment (total) & 0.03 & 0.11 & 0.16 & 0.23 & 0.22 & 0.23 & 0.27 & 0.41 & 0.68 \\
\hline Sup. Self-Employment (total in \%) &.-- & 1.1 & 1.6 & 2.0 & 2.2 & 2.3 & 2.7 & 4.6 & 8.9 \\
\hline
\end{tabular}

${ }^{a}$ Relative to the workforce.

${ }^{b}$ Relative to all unemployed.

${ }^{c}$ The figures for the years 1994-1998 are approximated.

Source: Bundesagentur für Arbeit, various issues.

Table 2: Design of the Programmes

\begin{tabular}{|c|c|c|}
\hline & Bridging Allowance & Start-Up Subsidy \\
\hline $\begin{array}{l}\text { Entry condi- } \\
\text { tions: }\end{array}$ & $\begin{array}{l}\text { Unemployment benefit entitlement } \\
\text { Approval of the business plan by an } \\
\text { external source (e.g. chamber of com- } \\
\text { merce) }\end{array}$ & $\begin{array}{l}\text { Unemployment benefit receipt } \\
\text { Approval of the business required since } \\
\text { November } 2004\end{array}$ \\
\hline Support: & $\begin{array}{l}\text { Participant receives UB for six months } \\
\text { To cover social security liabilities, an } \\
\text { additional lump sum of approx. } 70 \% \\
\text { is granted }\end{array}$ & $\begin{array}{l}\text { Participants receive a fixed sum } \\
\text { of } € 600 / \text { month in the first year, } \\
€ 360 / \text { month ( } € 240 / \text { month) in the } \\
\text { second (third) year } \\
\text { Claim has to be renewed every year, in- } \\
\text { come is not allowed to exceed } € 25,000 \\
\text { per year }\end{array}$ \\
\hline Other: & $\begin{array}{l}\text { Social security is left at the individual's } \\
\text { discretion }\end{array}$ & $\begin{array}{l}\text { Participants are required to join the le- } \\
\text { gal pension insurance and receive a re- } \\
\text { duced rate on the legal health insurance }\end{array}$ \\
\hline Details: & $\S 57(1)$ Social Code III. & $\S 421$ l Social Code III. \\
\hline
\end{tabular}


Table 3: Selected Descriptives

\begin{tabular}{|c|c|c|c|c|c|c|}
\hline \multirow[b]{2}{*}{ Variable } & \multicolumn{3}{|c|}{ Men } & \multicolumn{3}{|c|}{ Women } \\
\hline & NP & SUS & BA & NP & SUS & $\mathrm{BA}$ \\
\hline Number of observations & 593 & 371 & 448 & 350 & 276 & 202 \\
\hline Age (in years) & $\begin{array}{r}38.78 \\
(9.93)\end{array}$ & $\begin{array}{r}39.72 \\
(9.97)\end{array}$ & $\begin{array}{r}38.46 \\
(9.10)\end{array}$ & $\begin{array}{r}39.91 \\
(9.57)\end{array}$ & $\begin{array}{r}40.79 \\
(9.41)\end{array}$ & $\begin{array}{r}39.87 \\
(9.12)\end{array}$ \\
\hline Age $18-29$ & $\begin{array}{r}0.22 \\
(0.42)\end{array}$ & $\begin{array}{r}0.18 \\
(0.39)\end{array}$ & $\begin{array}{r}0.17 \\
(0.38)\end{array}$ & $\begin{array}{r}0.16 \\
(0.36)\end{array}$ & $\begin{array}{r}0.14 \\
(0.34)\end{array}$ & $\begin{array}{r}0.14 \\
(0.35)\end{array}$ \\
\hline Age $50-64$ & $\begin{array}{r}0.16 \\
(0.37)\end{array}$ & $\begin{array}{r}0.21 \\
(0.41)\end{array}$ & $\begin{array}{r}0.13 \\
(0.34)\end{array}$ & $\begin{array}{r}0.19 \\
(0.39)\end{array}$ & $\begin{array}{r}0.22 \\
(0.42)\end{array}$ & $\begin{array}{r}0.14 \\
(0.35)\end{array}$ \\
\hline $\begin{array}{l}\text { Qualification Variables } \\
\text { School Degree }\end{array}$ & & & & & & \\
\hline No/Low Degree & $\begin{array}{r}0.13 \\
(0.33)\end{array}$ & $\begin{array}{r}0.17 \\
(0.37)\end{array}$ & $\begin{array}{r}0.09 \\
(0.29)\end{array}$ & $\begin{array}{r}0.09 \\
(0.28)\end{array}$ & $\begin{array}{r}0.13 \\
(0.34)\end{array}$ & $\begin{array}{r}0.07 \\
(0.25)\end{array}$ \\
\hline Upper secondary schooling & $\begin{array}{r}0.29 \\
(0.45)\end{array}$ & $\begin{array}{r}0.27 \\
(0.44)\end{array}$ & $\begin{array}{r}0.34 \\
(0.47)\end{array}$ & $\begin{array}{r}0.33 \\
(0.47)\end{array}$ & $\begin{array}{r}0.33 \\
(0.47)\end{array}$ & $\begin{array}{r}0.45 \\
(0.50)\end{array}$ \\
\hline Job Qualification & & & & & & \\
\hline High Qualified & $\begin{array}{r}0.17 \\
(0.38)\end{array}$ & $\begin{array}{r}0.14 \\
(0.35)\end{array}$ & $\begin{array}{r}0.23 \\
(0.42)\end{array}$ & $\begin{array}{r}0.21 \\
(0.41)\end{array}$ & $\begin{array}{r}0.18 \\
(0.38)\end{array}$ & $\begin{array}{r}0.29 \\
(0.46)\end{array}$ \\
\hline Low Qualified & $\begin{array}{r}0.16 \\
(0.36)\end{array}$ & $\begin{array}{r}0.23 \\
(0.42)\end{array}$ & $\begin{array}{r}0.13 \\
(0.33)\end{array}$ & $\begin{array}{r}0.13 \\
(0.34)\end{array}$ & $\begin{array}{r}0.18 \\
(0.39)\end{array}$ & $\begin{array}{r}0.10 \\
(0.29)\end{array}$ \\
\hline Labour Market History & & & & & & \\
\hline Unemployment duration (in months) & $\begin{array}{r}240.14 \\
(236.01)\end{array}$ & $\begin{array}{r}260.02 \\
(252.38)\end{array}$ & $\begin{array}{r}220.61 \\
(212.78)\end{array}$ & $\begin{array}{r}276.77 \\
(306.00)\end{array}$ & $\begin{array}{r}301.28 \\
(326.80)\end{array}$ & $\begin{array}{r}229.92 \\
(238.51)\end{array}$ \\
\hline Unempl. Duration $<3$ months & $\begin{array}{r}0.26 \\
(0.44)\end{array}$ & $\begin{array}{r}0.27 \\
(0.45)\end{array}$ & $\begin{array}{r}0.28 \\
(0.45)\end{array}$ & $\begin{array}{r}0.24 \\
(0.43)\end{array}$ & $\begin{array}{r}0.24 \\
(0.43)\end{array}$ & $\begin{array}{r}0.31 \\
(0.46)\end{array}$ \\
\hline Unempl. Duration > 12 months & $\begin{array}{r}0.19 \\
(0.39)\end{array}$ & $\begin{array}{r}0.23 \\
(0.42)\end{array}$ & $\begin{array}{r}0.14 \\
(0.35)\end{array}$ & $\begin{array}{r}0.23 \\
(0.42)\end{array}$ & $\begin{array}{r}0.27 \\
(0.44)\end{array}$ & $\begin{array}{r}0.18 \\
(0.38)\end{array}$ \\
\hline Daily Unemployment Transfer (in Euro) & $\begin{array}{r}24.91 \\
(10.23)\end{array}$ & $\begin{array}{r}21.49 \\
(8.48)\end{array}$ & $\begin{array}{r}29.80 \\
(12.86)\end{array}$ & $\begin{array}{r}19.46 \\
(9.52)\end{array}$ & $\begin{array}{l}16.45 \\
(7.95)\end{array}$ & $\begin{array}{r}25.14 \\
(11.34)\end{array}$ \\
\hline Remaining Time of UB (in months) & $\begin{array}{r}5.33 \\
(6.28)\end{array}$ & $\begin{array}{r}4.22 \\
(5.95)\end{array}$ & $\begin{array}{r}6.32 \\
(6.34)\end{array}$ & $\begin{array}{r}3.66 \\
(5.23)\end{array}$ & $\begin{array}{r}3.34 \\
(4.98)\end{array}$ & $\begin{array}{r}5.78 \\
(6.59)\end{array}$ \\
\hline Average daily earnings in 2002 (in Euro) & $\begin{array}{r}29.74 \\
(33.07)\end{array}$ & $\begin{array}{r}21.73 \\
(24.32)\end{array}$ & $\begin{array}{r}45.90 \\
(38.98)\end{array}$ & $\begin{array}{r}19.49 \\
(26.30)\end{array}$ & $\begin{array}{r}14.03 \\
(17.26)\end{array}$ & $\begin{array}{r}34.03 \\
(34.31)\end{array}$ \\
\hline No. of placement propositions & $\begin{array}{r}4.35 \\
(5.29)\end{array}$ & $\begin{array}{r}3.94 \\
(5.59)\end{array}$ & $\begin{array}{r}3.45 \\
(6.45)\end{array}$ & $\begin{array}{r}5.44 \\
(6.49)\end{array}$ & $\begin{array}{r}4.35 \\
(5.84)\end{array}$ & $\begin{array}{r}3.37 \\
(4.82)\end{array}$ \\
\hline
\end{tabular}

Note: All variables are measured one month before program start. Standard deviations are in parentheses.

Table 4: Matching Quality — Some Indicators

\begin{tabular}{lllll}
\hline \hline Variable & \multicolumn{2}{c}{ Start-up Subsidy } & \multicolumn{2}{c}{ Bridging Allowance } \\
& Men & Women & Men & Women \\
\hline MSD - Before Matching & 9.18 & 7.40 & 15.10 & 19.43 \\
MSD - After Matching & 4.77 & 3.52 & 3.75 & 2.39 \\
$R^{2}$ - Before Matching & 0.11 & 0.11 & 0.10 & 0.14 \\
$R^{2}$ - After Matching & 0.03 & 0.02 & 0.01 & 0.01 \\
$\chi^{2}$ - Before Matching & 0.00 & 0.00 & 0.00 & 0.00 \\
$\chi^{2}$ - After Matching & 0.99 & 1.00 & 1.00 & 1.00 \\
Participants off support & 4 & 9 & 11 & 2 \\
\hline \hline
\end{tabular}

Note: Mean standardised difference (MSD) has been calculated as an unweighted average of the standardised difference of all covariates. Standardised difference before matching calculated as: $100 \cdot\left(\bar{W}_{1}-\right.$ $\left.\bar{W}_{0}\right) /\left\{\sqrt{\left(V_{1}(W)+V_{0}(W)\right) / 2}\right\}$ and standardised difference after matching calculated as: $100 \cdot\left(\bar{W}_{1 M}-\bar{W}_{0 M}\right) /\left\{\sqrt{\left(V_{1}(W)+V_{0}(W)\right) / 2}\right\}$. 
Table 5: Cumulated Effects - Matching and Conditional DiD

\begin{tabular}{lcccccccc}
\hline & \multicolumn{3}{c}{ Start-Up Subsidy } & \multicolumn{3}{c}{ Bridging Allowance } \\
Outcome & Effect & s.e & Effect & s.e & Effect & s.e & Effect & s.e \\
\hline \multicolumn{7}{c}{ Wen } & & \\
Outcome Variable A: Not Unemployed (in months) & & & \\
Matching & 13.85 & $(0.60)$ & 16.43 & $(0.65)$ & 11.67 & $(0.57)$ & 11.06 & $(0.85)$ \\
CDiD 1 & 14.13 & $(1.04)$ & 16.07 & $(1.67)$ & 10.97 & $(0.77)$ & 11.30 & $(0.99)$ \\
CDiD 2 & 14.12 & $(0.74)$ & 16.22 & $(0.92)$ & 11.24 & $(0.65)$ & 11.21 & $(0.89)$ \\
CDiD 3 & 13.86 & $(0.77)$ & 16.28 & $(1.02)$ & 11.40 & $(0.59)$ & 11.15 & $(0.84)$ \\
Outcome Variable B: Employed or Self-Employed (in months) & & \\
Matching & 15.53 & $(0.57)$ & 19.00 & $(0.81)$ & 13.22 & $(0.57)$ & 13.77 & $(0.93)$ \\
CDiD 1 & 16.87 & $(1.45)$ & 17.91 & $(2.01)$ & 11.26 & $(1.08)$ & 12.81 & $(1.94)$ \\
CDiD 2 & 16.94 & $(0.82)$ & 18.53 & $(1.15)$ & 12.60 & $(0.80)$ & 13.77 & $(1.18)$ \\
CDiD 3 & 15.46 & $(0.98)$ & 18.38 & $(1.45)$ & 11.88 & $(0.93)$ & 12.81 & $(1.56)$ \\
\hline \hline
\end{tabular}

Note: Matching estimates are based on kernel matching as discussed in Section 5.2. Standard errors (in parentheses) are based on 200 bootstrap replications.

Reference level for DiD 1: Total month not spend in unemployment (outcome variable A) and spend in regular employment (outcome variable B) between 1997 and 2002.

Reference level for DiD 2: Same as DiD-1, but for the time period 2000-2002.

Reference level for DiD 3: Same as DiD-1, but for the time period 1997-1999.

Table 6: Effects on Monthly Income - Matching and Conditional DiD

\begin{tabular}{|c|c|c|c|c|c|c|c|c|}
\hline \multirow[b]{3}{*}{ Outcome } & \multicolumn{4}{|c|}{ Start-up Subsidy } & \multicolumn{4}{|c|}{ Bridging Allowance } \\
\hline & \multicolumn{2}{|c|}{ Men } & \multicolumn{2}{|c|}{ Women } & \multicolumn{2}{|c|}{ Men } & \multicolumn{2}{|c|}{ Women } \\
\hline & Effect & s.e & Effect & s.e & Effect & s.e & Effect & s.e \\
\hline \multicolumn{9}{|c|}{ Effect on Monthly Income from Self-Employment/Regular Employment (in $€$ ) } \\
\hline Matching & 580.60 & $(75.06)$ & 321.76 & $(96.04)$ & 817.57 & $(102.52)$ & 286.03 & $(145.01)$ \\
\hline CDiD 1 & 619.97 & $(87.76)$ & 302.48 & $(102.28)$ & 767.50 & $(108.25)$ & 263.01 & $(142.63)$ \\
\hline CDiD 2 & 693.12 & $(74.92)$ & 331.07 & $(112.12)$ & 717.46 & $(113.95)$ & 257.26 & $(124.39)$ \\
\hline CDiD 3 & 687.77 & $(101.54)$ & 294.67 & $(128.96)$ & 721.79 & $(118.19)$ & 280.84 & $(124.93)$ \\
\hline \multicolumn{9}{|c|}{ Effect on Total Monthly Income (in $€$ ) } \\
\hline Matching & 398.62 & $(79.55)$ & 163.60 & $(83.67)$ & 666.90 & $(102.58)$ & 219.18 & $(119.97)$ \\
\hline CDiD 1 & 437.98 & $(78.64)$ & 144.33 & $(102.60)$ & 616.83 & $(96.39)$ & 196.16 & $(144.22)$ \\
\hline CDiD 2 & 511.13 & $(83.58)$ & 172.92 & $(103.05)$ & 566.79 & $(97.28)$ & 190.41 & (147.34) \\
\hline CDiD 3 & 505.78 & $(80.76)$ & 136.52 & $(102.43)$ & 571.13 & $(102.22)$ & 213.99 & $(126.35)$ \\
\hline
\end{tabular}

Note: Matching estimates are based on kernel matching as discussed in Section 5.2. Standard errors (in parentheses) are based on 200 bootstrap replications.

Reference level for DiD 1: Unemployment Benefit before programme start.

Reference level for DiD 2: Average monthly income in 2002.

Reference level for DiD 3: Average monthly income from regular employment in 2002. 
Table 7: Direct Employment Effects after 28 Months and Future Development ${ }^{1}$

\begin{tabular}{|c|c|c|c|c|}
\hline & \multicolumn{2}{|c|}{$\begin{array}{l}\text { Start-Up } \\
\text { Subsidy }\end{array}$} & \multicolumn{2}{|c|}{$\begin{array}{c}\text { Bridging } \\
\text { Allowance }\end{array}$} \\
\hline & Men & Women & Men & Women \\
\hline \multirow[t]{2}{*}{ Start-ups with employees } & 0.081 & 0.089 & 0.280 & 0.223 \\
\hline & $(0.27)$ & $(0.29)$ & $(0.45)$ & $(0.42)$ \\
\hline \multirow[t]{2}{*}{ Number of employees (mean) } & 2.000 & 1.474 & 4.011 & 2.355 \\
\hline & $(1.98)$ & $(0.77)$ & $(5.10)$ & $(1.40)$ \\
\hline \multirow[t]{2}{*}{ Share of regular employees } & 0.250 & 0.307 & 0.564 & 0.309 \\
\hline & $(0.44)$ & $(0.45)$ & $(0.43)$ & $(0.39)$ \\
\hline \multicolumn{5}{|l|}{ Employees in the future? } \\
\hline \multirow[t]{2}{*}{ Yes, surely } & 0.053 & 0.036 & 0.098 & 0.112 \\
\hline & $(0.23)$ & $(0.19)$ & $(0.30)$ & $(0.32)$ \\
\hline \multirow[t]{2}{*}{ Rather yes } & 0.214 & 0.129 & 0.256 & 0.168 \\
\hline & $(0.41)$ & $(0.34)$ & $(0.44)$ & $(0.38)$ \\
\hline \multirow[t]{2}{*}{ Rather no } & 0.359 & 0.335 & 0.342 & 0.206 \\
\hline & $(0.48)$ & $(0.47)$ & $(0.48)$ & $(0.41)$ \\
\hline \multirow[t]{2}{*}{ No, by no means } & 0.374 & 0.500 & 0.303 & 0.514 \\
\hline & $(0.48)$ & $(0.50)$ & $(0.46)$ & $(0.50)$ \\
\hline
\end{tabular}

${ }^{1}$ Numbers are shares unless stated otherwise; standard deviation in parentheses. Measured at the second interview after 28 months. 
Figure 1: Distribution of the Propensity Scores - Common Support ${ }^{1}$

Men

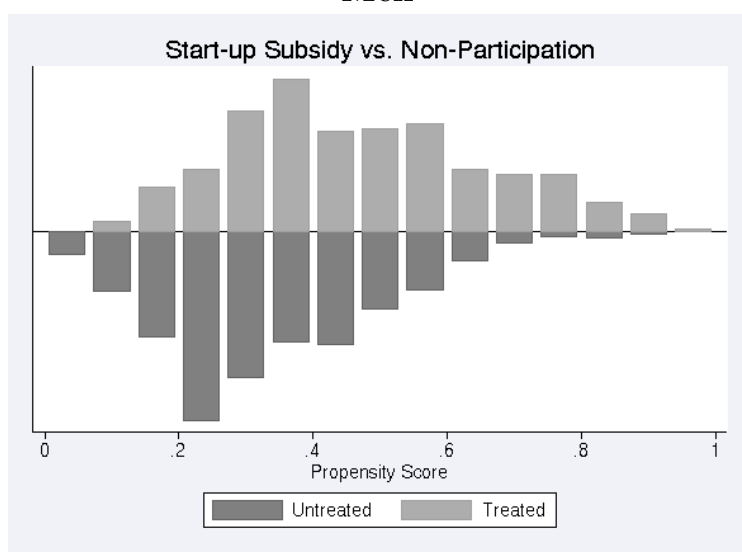

Bridging Allowance vs. Non-Participation

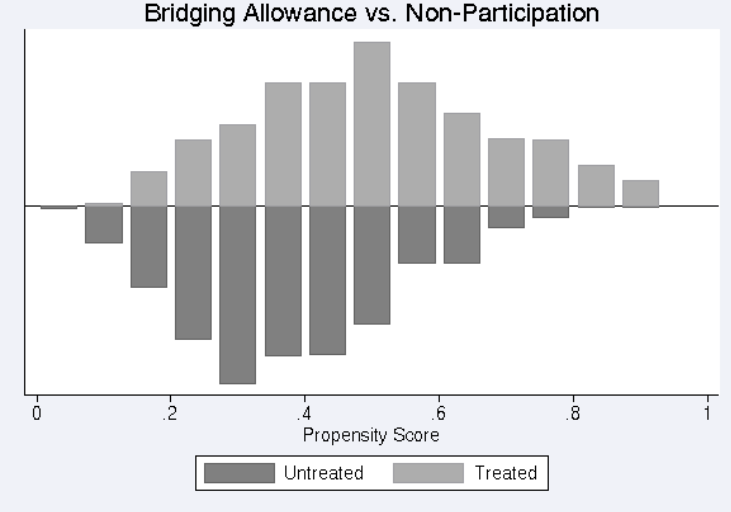

Women

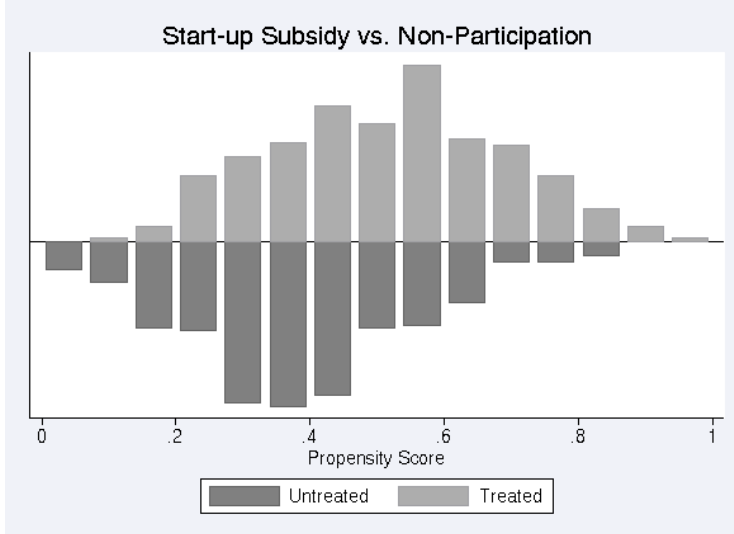

Bridging Allowance vs. Non-Participation

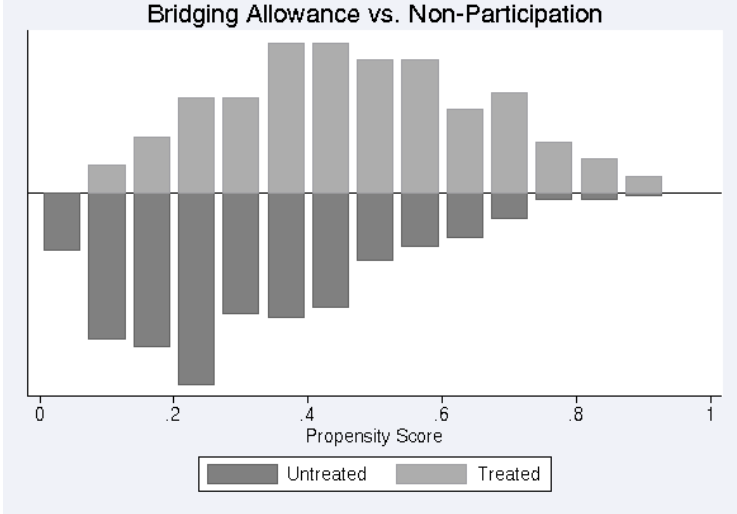

Note: Propensity score is estimated according to the specification in Table A.1. Participants are depicted in the upper half, nonparticipants in the lower half of each figure. 
Figure 2: Treatment Effects over Time

Men

Women

Outcome Variable A: Not Unemployed
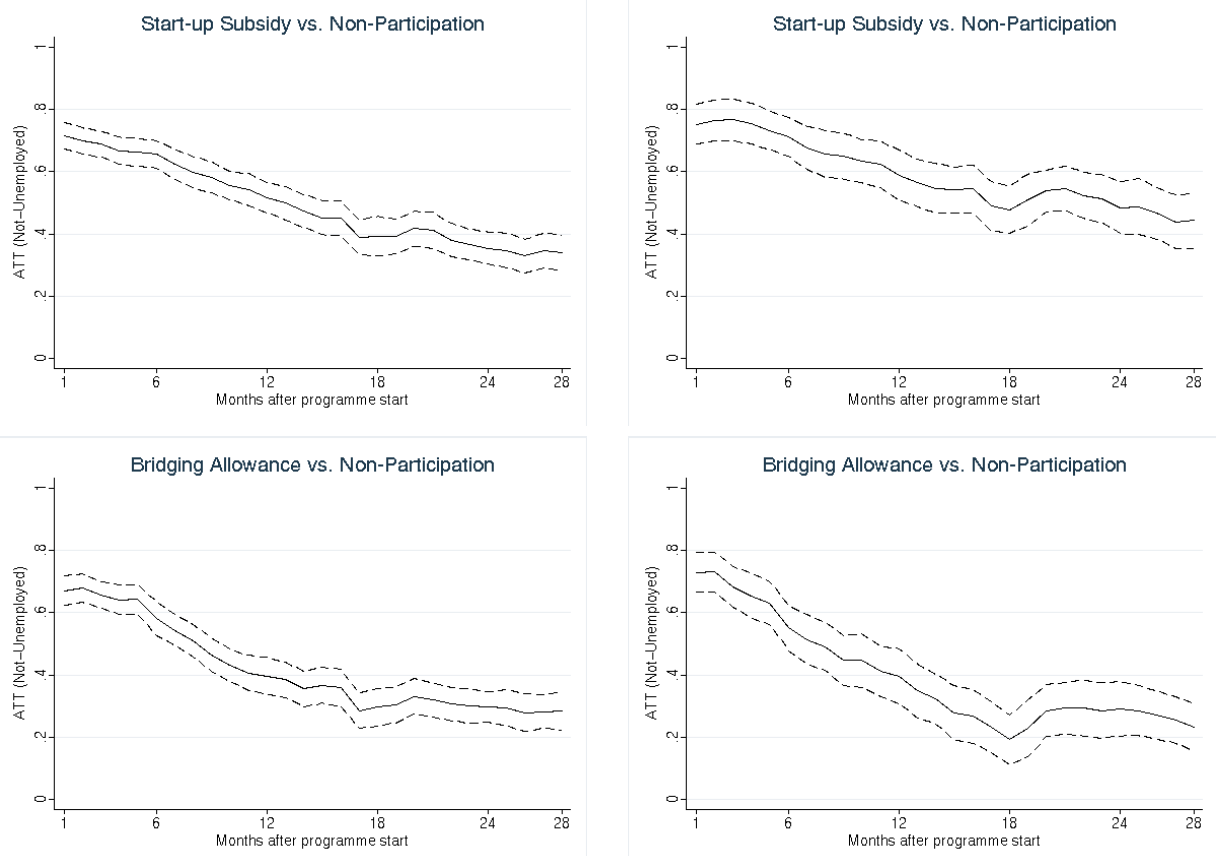

Outcome variable B: Employed or Self-Employed
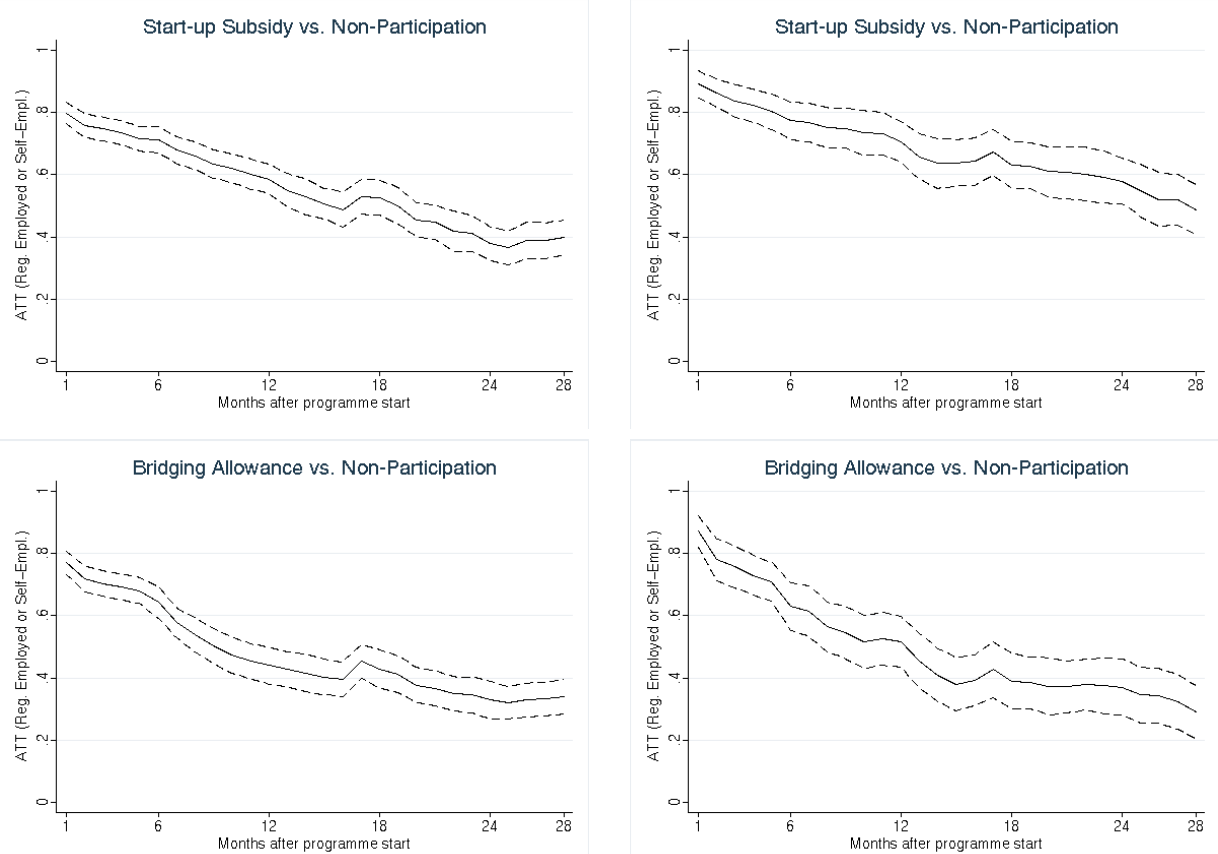

Note: Estimations are based on kernel matching as described in Section 5.2. Bootstrapped standard errors are based on 200 replications. 


\section{Appendix}

Table A.1: Propensity Score Estimation Results - Coefficients ${ }^{a}$

\begin{tabular}{|c|c|c|c|c|}
\hline & \multicolumn{2}{|c|}{ SUS vs. Non-Participation } & \multicolumn{2}{|c|}{ BA vs. Non-Participation } \\
\hline & Men & Women & Men & Women \\
\hline \multicolumn{5}{|l|}{ Socio-demographic characteristics } \\
\hline \multicolumn{5}{|l|}{ Age category } \\
\hline $25-29$ & 0.184 & 0.375 & -0.147 & -0.252 \\
\hline $30-34$ & $0.925 *$ & 0.746 & 0.463 & 0.08 \\
\hline $35-39$ & 0.365 & 0.584 & -0.003 & 0.151 \\
\hline $40-44$ & 0.527 & 0.679 & 0.095 & -0.13 \\
\hline $45-49$ & 0.656 & $0.967+$ & -0.391 & 0.412 \\
\hline $50-64$ & $1.422 * *$ & $1.018 *$ & -0.107 & -0.186 \\
\hline \multicolumn{5}{|l|}{ Children (Ref.: No children) } \\
\hline One child & 0.255 & 0 & -0.028 & -0.289 \\
\hline Two or more children & $0.484+$ & 0.051 & -0.009 & 0.023 \\
\hline \multicolumn{5}{|l|}{ Qualification variables } \\
\hline \multicolumn{5}{|l|}{ School degree } \\
\hline Lower secondary schooling & 0.433 & -1.33 & 0.413 & -1.173 \\
\hline Middle secondary schooling & 0.331 & -1.376 & 0.381 & -1.131 \\
\hline Specialised upper sec. schooling & 0.511 & -0.992 & 0.147 & -1.146 \\
\hline Upper secondary schooling & 0.342 & -1.021 & 0.338 & -1.196 \\
\hline \multicolumn{5}{|c|}{ Occupational group in previous profession (Ref.: manufacturing) } \\
\hline Agriculture & -0.251 & 0.095 & -0.331 & 0.285 \\
\hline Technical & 0.508 & $0.945+$ & 0.199 & $1.357 *$ \\
\hline Services & 0.271 & 0.369 & -0.018 & $0.828+$ \\
\hline Other & -0.274 & 0.031 & -0.424 & -0.121 \\
\hline \multicolumn{5}{|l|}{ Job Qualification } \\
\hline Idiwquali0 & $-0.613+$ & -0.552 & -0.344 & -0.31 \\
\hline Idiwquali1 & -0.129 & $-0.862+$ & -0.241 & -0.42 \\
\hline Idiwquali2 & $-0.406 *$ & -0.209 & -0.164 & -0.282 \\
\hline \multicolumn{5}{|l|}{ Labour market history } \\
\hline \multicolumn{5}{|l|}{ Duration of last unemployment } \\
\hline 3 months $-<6$ months & $-0.458 *$ & -0.155 & $-0.366+$ & -0.367 \\
\hline 6 months $-<1$ year & -0.075 & -0.33 & 0.134 & -0.155 \\
\hline$\geq 1$ year & -0.032 & 0.017 & 0.111 & 0.155 \\
\hline With work experiences & 0.295 & -0.387 & 0.007 & -0.198 \\
\hline Number of placement propositions & -0.016 & $-0.043 *$ & 0.004 & $-0.040+$ \\
\hline Unemployment benefits & $-0.044 * *$ & $-0.043 * *$ & $0.026 *$ & $0.047 * *$ \\
\hline Remaining benefit entitlement & $-0.032+$ & $-0.054 *$ & $-0.037 *$ & -0.029 \\
\hline \multicolumn{5}{|l|}{ Daily income from regular employment } \\
\hline 1999 & 0.001 & 0.002 & 0 & 0.005 \\
\hline 2000 & -0.006 & 0.007 & 0.009 & -0.007 \\
\hline 2001 & 0.012 & -0.007 & $0.012+$ & 0.004 \\
\hline 2002 & $-0.018 *$ & $-0.026 * *$ & -0.005 & -0.001 \\
\hline Constant & -1.705 & 0.836 & -0.711 & -1.375 \\
\hline Log-likelihood & -570.413 & -382.851 & -642.031 & -312.972 \\
\hline Hit-Rate & 41.805 & 48.182 & 45.521 & 42.5 \\
\hline
\end{tabular}

Note: $* * / * /+$ indicates significance at the $1 \% / 5 \% / 10 \%$ level.

Additional variables included: Family status, health restrictions, nationality, desired working time, job qualification, months spend in regular employment and unemployment in the years 1999, 2000, 2001, and 2002, employment status before unemployment, and dummy variables for the regional labour market context (strategy clusters). Full estimation results and marginal effects are available on request by the authors. 
Table A.2: Cross-Validation for the Bandwidth Selection

\begin{tabular}{cccccccc}
\hline \hline \multicolumn{3}{c}{ Start-Up Subsidy } & \multicolumn{4}{c}{ Bridging Allowance } \\
$\mathrm{h}$ & $\mathrm{RMSE}$ & $\mathrm{h}$ & $\mathrm{RMSE}$ & $\mathrm{h}$ & $\mathrm{RMSE}$ & $\mathrm{h}$ & $\mathrm{RMSE}$ \\
\hline 0.26977 & 0.49927 & 0.00091 & 0.52211 & 0.15221 & 0.49511 & 0.09469 & 0.49172 \\
0.27977 & 0.49925 & 0.01091 & 0.47566 & 0.16221 & 0.49508 & 0.10469 & 0.49172 \\
0.28977 & 0.49924 & 0.02091 & 0.48550 & 0.17221 & 0.49510 & 0.11469 & 0.49162 \\
0.29977 & 0.49923 & 0.03091 & 0.49064 & 0.18221 & 0.49511 & 0.12469 & 0.49137 \\
0.30977 & 0.49924 & 0.04091 & 0.49283 & 0.19221 & 0.49503 & 0.13469 & 0.49113 \\
0.31977 & 0.49923 & 0.05091 & 0.49508 & 0.20221 & 0.49497 & 0.14469 & 0.49094 \\
0.32977 & 0.49923 & 0.06091 & 0.49720 & 0.21221 & 0.49497 & 0.15469 & 0.49074 \\
0.33977 & 0.49923 & 0.07091 & 0.49842 & 0.22221 & 0.49505 & 0.16469 & 0.49080 \\
0.34977 & 0.49924 & & & 0.23221 & 0.49510 & 0.17469 & 0.49088 \\
0.35977 & 0.49925 & & & 0.24221 & 0.49514 & 0.18469 & 0.49096 \\
0.36977 & 0.49926 & & & 0.25221 & 0.49516 & 0.19469 & 0.49114 \\
\hline \hline
\end{tabular}

Note: We implement leave-one out cross-validation in a five step procedure (see, e.g., Galdo, 2005):

1. Define a bandwidth search grid. Here, we use $l_{b w}+0.05 \times g$ for $g=0,1,2, \ldots, 20$, where $l_{b w}=\max \left[\min \left[\left|P_{0 i}-P_{0-i}\right|,\left|P_{0 i}-P_{0+i}\right|\right]\right]$ is a lower bound defined by the propensity score values of comparison group members in the support region.

2. Starting with the lowest bandwidth and using only the comparison sample, estimate the counterfactual outcome of each comparison unit using kernel matching on the remaining $N_{0}-1$ observations. Find the weighted MISE for that particular bandwidth.

3. Repeat step 2 for each of the remaining bandwidth values. Find the particular bandwidth $h^{+}$that minimizes the weighted MISE across all estimations.

4. Refine the bandwidth $h^{+}$by defining a $+/-0.05$ neighborhood around $h^{+}$and select a new search grid.

5. Repeat steps 2 and 3 and select the bandwidth that yields the minimum weighted $M I S E$ among all estimations. 